\title{
ポーラログラフ法によるクロム $(\mathrm{II})$-オキシェチルエチレンジアミン三酢酸錯体の錯形成反応
}

(昭和 42 年 7 月 13 日受理)

引地 宏*1. 田 中 信 行*2

滴下水銀電極におけるへキサフンミンクロム(II)イオンの一電子還元波は，マンガン(II)イオンおよびマンガン(II)ーオキシエチ ルエチレンジフミン三酷酸(HEDTA と略記)錯体が存在するとき，2 段に分裂する。とれはつぎのような電極反応

$\left[\mathrm{Cr}\left(\mathrm{NH}_{3}\right)_{6}\right]^{3+}+e \longrightarrow \mathrm{Cr}_{\mathrm{aq}}^{2+}+6 \mathrm{NH}_{3}$

$\mathrm{MnX}^{-}+j \mathrm{H}^{+} \rightleftarrows \mathrm{Mn}_{\mathrm{aq}}^{2+}+\mathrm{H}_{j} \mathrm{X}^{(3-j)-}$

$\mathrm{Cr}_{\mathrm{aq}}^{2+}+\mathrm{H}_{j} \mathrm{X}^{(3-j)-} \underset{k_{\overline{\mathrm{H}} j \mathrm{X}}}{\stackrel{k_{\mathrm{H}}^{+} \mathrm{XX}}{\rightleftarrows}} \mathrm{CrX} \mathrm{X}^{-}+j \mathrm{H}^{+}$

(ただし $j=0,1)$

$\mathrm{CrX} \mathrm{X}^{-} \longrightarrow \mathrm{CrX}+e$

に基づくものであるが，その第 1 波の限界電流值は適当な条件では，クロム（II)イオンと HEDTA との錯形成反応の 速度に依存

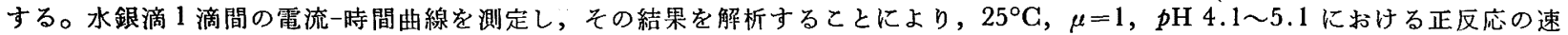
度定数 $k_{\mathrm{X}}^{+}, k_{\mathrm{H} \mathrm{X}}^{+}$として, $k_{\mathrm{X}}^{+}=5.7 \times 10^{10} l \cdot \mathrm{mol}^{-1} \cdot \mathrm{sec}^{-1}, k_{\mathrm{H} \mathrm{X}}^{+}=1 .{ }_{2} \times 10^{5} l \cdot \mathrm{mol}^{-1} \cdot \mathrm{sec}^{-1}$ の值を得た。

\section{1 緒言}

一般に，クロム (II )錯体は酸化を受けやすく，その点で不安定 なためこれらの生成定数および反応速度定数についての研究は比 較的少なく, 最近エチレンジミンテトラアセタト(以下 EDTA と略記)錯体 つ 3)について二三報告されているのみである。この 種の反応，すなわち遷移金属元素の 2 価イオンの錯形成反応は配 位子場理諭とも関連して，哭機反応論においてとくに興味のある 問題であることを考慮し，本研究では，配位子としてオキシエチ ルエチレンジアミン三酶酸(以下 HEDTA と略記； $\mathrm{H}_{3} \mathrm{X}$ )を取り あげ，錯形成反応を研究した。

HEDTA と 2 価金属イオンの錯形成反态については，さきに 藤沢ら4) が先行反応に基づくポーラログラフィ一反応電流を利用 して，反応速度定数安求めている。しかし 2 佂クロムイオンの場 合には，その方法を適用することが困難なため，後続反応に基づ く反応電流を利用する方法を適用した。すなわちクロム（II）溶液 を調製することなく，マンガン(II)-HEDTA および $\mathrm{Mn}_{\mathrm{aq}}^{2+}$ イ オンを含む溶液中で, ヘキサアンミンクロム（II)イオンのポーラ ログラムおよび 水銀滴 1 滴間の電流-時間曲線を測定し，それら の解析から反応機構および反応速度定数を决定した。

\section{2 実験}

\section{1 試 薬}

ヘキサアンミンクロム( II)塩化物は森の方法5)で合成した。そ の水溶液はあまり安定でないため，使用するごとに調製した。ま た硝酸亜鉛の標準溶液は，純亜鉛(99.999\%)を希硝酸に溶かし，

*1 Hiroshi HrkıchI 福島工業高等専門学校工業化学科, い わき市平上荒川

*2 Nobuyuki TANAKA 東北大学理学部化学教室，仙台市 片平丁

1) R. L. Pecsok, L. D. Shields, W. P. Schaefer, Inorg. Chem., 3, 114(1964).

2) N. Tanaka, K. Ebata, J. Electroanal. Chem., 8, 120 (1964).

3) N. Tanaka, K. Ogino, Bull. Chem. Soc. Japan, 39, 22672(1966).

4) 藤沢 忠, 田中信行，日化，88，734(1967)。

5）森 正保，日化，74，253(1953)。
過剩の硝酸を蒸発して $p \mathrm{H}$ を約 4.0 に調整した。その他の試薬 はすべて特級品を使用した。

EDTA 溶液, HEDTA 溶液の浱度は硝酸亚鉛標準溶液を用い, pH 4.7 の酰酸塩緩衝溶液中で電流滴定法により標定し，また塩 化マンガン (II)溶液の 濃度は標定した EDTA 溶液を用い， $p \mathrm{H}$ 8.0 のアンモニアーアンモニウム塭緩衝溶液中で電流滴定法 ${ }^{6)}$ に より決定した。

\section{2 装 置}

使用した 滴下水銀電極の特性は, $0.10 \mathrm{~mol} / l$ 酶酸緩衝液 $(p \mathrm{H}$ $4.7), 0.90 \mathrm{~mol} / l$ 塩化ナトリウム, $0.006 \%$ ゼラチンの溶液中, 水銀圧 $55 \mathrm{~cm},-0.5 \mathrm{~V}$ vs. SGE の条件で, 水銀の流出量 $(m)=$ $1.70_{9} \mathrm{mg} / \mathrm{sec}$ ，滴下時間 $\left(t_{d}\right)=4.75 \mathrm{sec}$ であった。

電流一電位曲線はペン記録式直流ポーラログラフ(柳本 AP-1 型) で記録し，水銀滴 1 滴間の電流-時間曲線の 記録には 理化電機 $\mathrm{ER}-\mathrm{J} 1$ 型記録計を使用した。 $p \mathrm{H}$ の測定には堀場の $\mathbf{P}$ 型精密 $p \mathrm{H}$ メーターを用いた。測定はすべて $25 \pm 0.1^{\circ} \mathrm{C}$ の恒温槽中で行な った。

\section{3 結果および考察}

\subsection{HEDTA の影響}

ヘキサアンミンクロム (III)イオンの一電子還元波は，HEDTA が共存すると図 1 に示したように変化する。すなわち，HEDTA の濃庋がへキサアンミンクロム (III)イオンの濃度より小さい場合 には 2 段にわかれ，その第 1 段目の波は立ち上りが鋭く，電位 はヘキサアンミンクロム（III)イオンの還元電位 $-0.89 \mathrm{~V}$ vs. SGE よりいくぶん負となる。他方 HEDTA が過剩になると，第 1 段 波は消滅し，第 2 段目の波のみとなる。この第 2 段波は可逆波の 性質を示し，その半波電位は $-1.23 \mathrm{~V}$ vs. SGE である。

この現象は EDTA を含む溶液中のへキサアンミンクロム（III イオンのポーラログラフ波の挙動233)てをったく同一であり，し たがって，HEDTA が存在する場合の電極反応機䪞も EDTA の 存在する場合と同様につぎのように考えられる。ただし $\mathrm{X}^{3-}$ は

6) G. Michel, Anal. Chim. Acta, 10, 87(1954).

7) K. Ebata, Sci. Repts., Töhoku Univ., Vol. XLVII, 4, 191 (1964). 


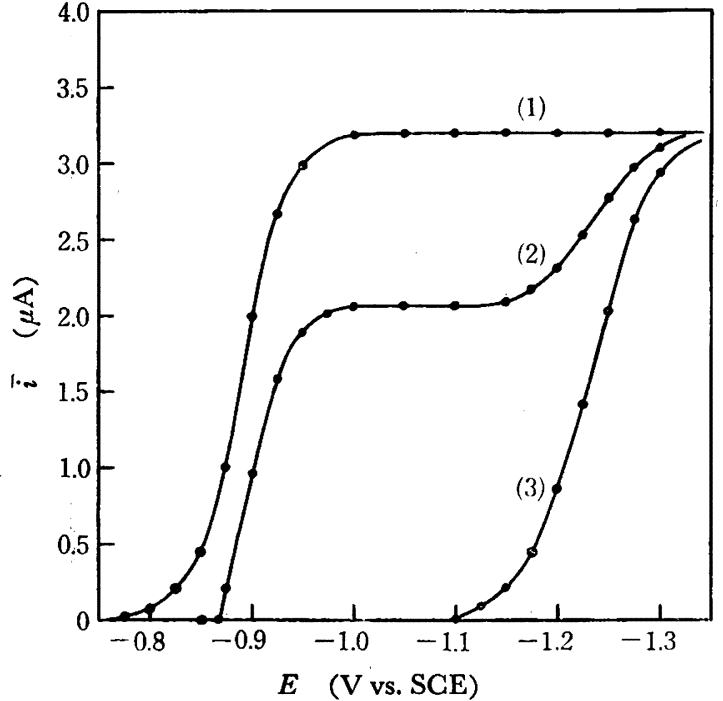

$1.00 \mathrm{mmol} / l\left[\mathrm{Cr}\left(\mathrm{NH}_{3}\right)_{6}\right] \mathrm{Cl}_{3}+0.10 \mathrm{~mol} / l$ 酶酸緩衝液 $+0.006 \%$ ゼラチン+(1) 0 , (2) $0.408 \mathrm{mmol} / l$ HEDTA, ( 3 ) $2.04 \mathrm{mmol} / l$ HEDTA

pH 4.65 4.66

因 1 ヘキサアンミンクロム(II)イオンの還元波に 扎よぼす HEDTA の影樂

HEDTA の 3 価の陰イオンである。

$$
\begin{aligned}
& {\left[\mathrm{Cr}\left(\mathrm{NH}_{3}\right)_{6}\right]^{3+}+e \longrightarrow\left[\mathrm{Cr}\left(\mathrm{NH}_{3}\right)_{6}\right]^{2+}} \\
& {\left[\mathrm{Cr}\left(\mathrm{NH}_{3}\right)_{6}\right]^{2+} \longrightarrow \mathrm{Cr}_{\mathrm{aq}}^{2+}+6 \mathrm{NH}_{3}} \\
& \mathrm{Cr}_{\mathrm{a}}^{2+}+\mathrm{H}_{j} \mathrm{X}^{(3-j)-} \stackrel{k_{f}}{\rightleftharpoons} \mathrm{CrX}^{-}+j \mathrm{H}^{+} \\
& \quad(j=0,1,2,3)
\end{aligned}
$$$$
\mathrm{CrX}-\longrightarrow \mathrm{CrX}+e
$$

第 1 段波の電位では電極表面に生成した $\mathrm{CrX}$ - が容易に電解酸 化され，そのために還元電流が減少すると考えられる。

このことを確かめるために, 過剩の HEDTA を含む溶液中で ヘキサアンミンクロム(III)イオンを第 1 段波の電位 $-1.05 \mathrm{~V}$ vs. SCE で定電位電解し, 得られた溶液の吸収スペクトルを 測定し た。その結果を合成したクロム（III)-HEDTA 錯体の吸収スペク トルと比較し, 第 1 吸収帯, 第 2 吸収带の極大の波数が一致する ことから, 溶液中にクロム(II)-HEDTA 錯体が生成しているこ とを確認した。

加えた HEDTA の量と第 1 段波の限界電流值の減少および第 1段波の立ち上りが鋭いことから，クロム（II)イオンと HEDTA の反応速度は，EDTA の場合と同様にきわめて 速いと考えられ る。

クロム (II)イオンと HEDTA の錯形成反応の速度を本法によ って求めるためには, 遊離の HEDTA イオンの潠度を減少する 必要があるが, 本研究では, マンガン(II)-HEDTA 鍇体とマン ガン (II)塩を配位子緩衙刜の形で用い, 遊離の HEDTA イオン の濃度を小さくするとともに一定にたもった。

\section{2 マンガン(II)-HEDTA 錯体の影響}

HEDTA のかわりに, マンガン(II)-HEDTA 錯体およびマン ガン (II)塩を添加した場合にも, 図 2 に示すように HEDTA の みのときと同じ電位領域で電流值の減少を示すが，その立ち上り はゆるやかである。またへキサアンミンクロム ( II)錯体の濃庑に
くらべてかなり過剩にマンガン(I )-HEDTA 錯体を添加しても 第 1 段波は消失しない。この場合の式 $(1 \mathrm{~b})$ に相当する 反応は, つぎの式( 2 )および式(1 b )で示されるものである。

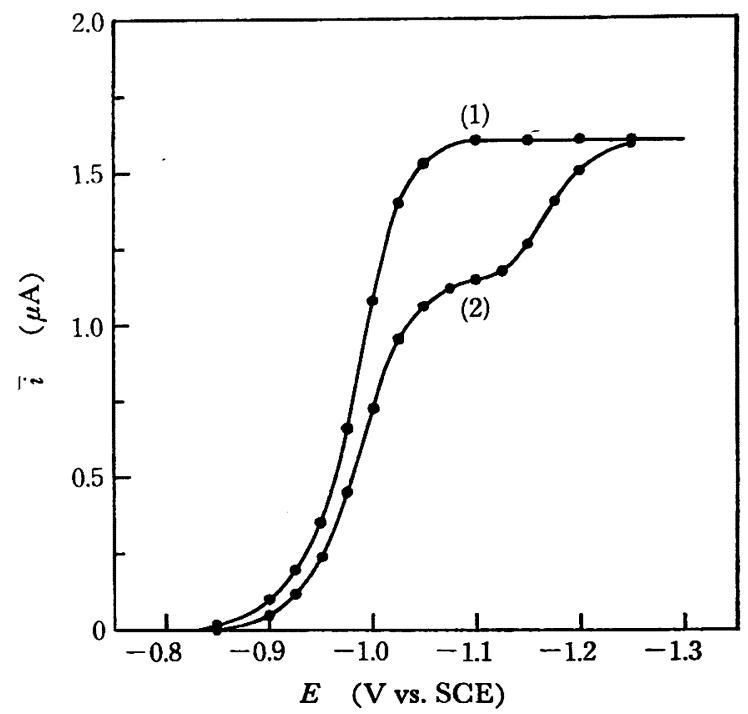

$0.500 \mathrm{mmol} / l\left[\mathrm{Cr}\left(\mathrm{NH}_{3}\right)_{6}\right] \mathrm{Cl}_{3}+0.10 \mathrm{~mol} / l$ 酶酸楥衝液 $+0.006 \%$ ゼラチン+( 1 ) $0.096_{0} \mathrm{~mol} / l$ 塩化マンガン (II), ( 2 ) $0.096_{0} \mathrm{~mol} / l$ 塩化マンガン(I) $+5.21_{3}$ mmol $/ l$ HEDTA

$\mu=1.0, \mathrm{NaCl}, p \mathrm{H} 4.92$

四 2 ヘキサアンミンクロム(II)イオンの還元波におよほす マンガン(I)-HEDTA 錯体の影響

$$
\begin{aligned}
& \mathrm{MnX}^{-}+j \mathrm{H}^{+} \rightleftharpoons \mathrm{Mn}_{\mathrm{aq}}^{2+}+\mathrm{H}_{j} \mathrm{X}^{(3-j)-} \\
& \mathrm{Cr}_{\mathrm{aq}}^{2+}+\mathrm{H}_{j} \mathrm{X}^{(3-j)-} \underset{k_{b}}{\stackrel{k_{f}}{\rightleftharpoons}} \mathrm{CrX}-+j \mathrm{H}^{+}
\end{aligned}
$$

実際の測定では，電極表面における $\mathrm{H}_{j} \mathbf{X}^{(3-j)}$ - の濃度を一定に たもつために, $\mathrm{MnX}$ およよ゙ $\mathrm{Mnaq}_{\mathrm{aq}}^{2+}$ イオンを十分過剩に加え た。

$$
\begin{aligned}
& \mathrm{MnX}^{-} \text {を添加するので, 式 (3) } \\
& \mathrm{Cr}_{\mathbf{a q}}^{2+}+\mathrm{MnX}^{-} \rightleftharpoons \mathrm{CrX}-+\mathrm{Mn}_{\mathbf{a q}}^{2+}
\end{aligned}
$$

で示すような $\mathrm{MnX}$ - イオンと $\mathrm{Cr}_{\mathrm{aq}}^{2+}$ イオンの直接の反応む考 えられる。この場合の反応速度は, $\mathrm{MnX}-$ イオンの濃度が一定 のとき $\mathrm{Mn}_{\mathrm{aq}}^{2+}$ イオンの濃度に依存しない。しかし実際には，後 述するように $\mathrm{Mn}_{\mathrm{aq}}^{2+}$ イオンの濃度に逆比例することが見いださ れているので, 式(3)の反応は遅く無視できるものと考えられ る。またヘキサアンミンクロム（）錯体の濃度に対する電流值の 比例性から, 反応 $(2)$ が律速段階となるような反応機構は考虑し なくてもよいことが判明した。

以上の実験事実から，マンガン（I )-HEDTA および Mn オンを含む溶液中のヘキサアンミンクロム（I）イオンの電極反応 は式(1a)，(1b)，(1c)で表わされると考えることができる。この場 合の解析はさきに報告されており37)8，それによると式(1a)およ び式(1c)の電極反応が十分に速いときには，一次反応速度定数 $\boldsymbol{l}_{\boldsymbol{f}}$ と瞬間電流 $i$ の間には次式が成立する。

$$
l_{f}=-\frac{1}{t} \ln \frac{i}{i_{d}}
$$

8) K. Ogino, N. Tanaka, Bull. Chem. Soc. Japan, 40, 1119 (1967). 


$$
l_{f}=\sum_{j=0}^{3} k_{\mathrm{II}} \mathrm{x}\left[\mathrm{H}_{j} \mathrm{X}^{(3-j)-}\right]
$$

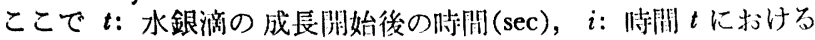
電流 $(\mu \mathrm{A}) ， i_{d}$ ：反応 $(1 \mathrm{a})$ ) みが進行与る場命の $t$ に怙ける電流 $(\mu \mathrm{A})$ を示す。

$$
K_{\mathrm{MnX}}=\frac{\left[\mathrm{MnX}^{-}\right]}{\left[\mathrm{Mn}^{2+}\right]\left[\mathrm{X}^{3-}\right]}, K_{\mathrm{HX}}=\frac{\left[\mathrm{H}^{+}\right]\left[\mathrm{X}^{3-}\right]}{\left[\mathrm{HX}^{2-}\right]}
$$

であるから， $l_{f}$ は

$$
l_{f}=\frac{k_{\mathrm{X}}\left[\mathrm{MnX}^{-}\right]}{K_{\mathrm{MnX}}\left[\mathrm{Mn}^{2+}\right]}+\sum_{j=1}^{3} \frac{k_{\mathrm{H} j \mathrm{x}}\left[\mathrm{H}^{+}\right]^{j}\left[\mathrm{MnX}^{-}\right]}{\beta_{\mathrm{H} j \mathrm{X}} K_{\mathrm{MnX}}\left[\mathrm{Mn}^{2+}\right]}
$$

のように表わされる。

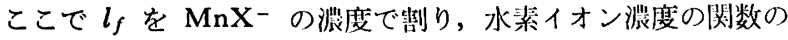
形に書き換えると，

$$
\begin{aligned}
F(\mathrm{H}) & \equiv l_{f} /\left[\mathrm{MnX}_{\mathrm{X}^{-}}\right] \\
& =\frac{k_{\mathrm{MnX}}\left[\mathrm{Mn}^{2+}\right]}{K}+\frac{k_{\mathrm{HX}}\left[\mathrm{H}^{+}\right]}{K_{\mathrm{MnX}} K_{\mathrm{HX}}\left[\mathrm{Mn}^{2+}\right]} \\
& +\sum_{j=2}^{3} \frac{k_{\mathrm{H} j \mathrm{X}}}{\beta_{\mathrm{H} j \mathrm{X}} K_{\mathrm{MnX}}\left[\mathrm{Mn}^{2+}\right]}\left[\mathrm{H}^{+}\right]^{j}
\end{aligned}
$$

さらに $\mathrm{Mn}_{\mathrm{a} a}^{2+}$ イオンの濃度の関数の形に書き捘えると， $F(\mathrm{Mn}) \equiv l_{f} /\left[\mathrm{MnX}^{-}\right]$

$$
=\left(\frac{k_{\mathrm{X}}}{K_{\mathrm{MnX}}}+\frac{k_{\mathrm{HX}}\left[\mathrm{H}^{+}\right]}{K_{\mathrm{MnX}} K_{\mathrm{HX}}}+\sum_{j=2}^{3} \frac{k_{\mathrm{H} j \mathrm{X}}\left[\mathrm{H}^{+}\right]^{j}}{\beta_{\mathrm{H} j \mathrm{X}} K_{\mathrm{MnX}}}\right) /
$$$$
\left[\mathrm{Mn}^{2+}\right]
$$

が得られる。

そこで， $\mathrm{Mn}_{\mathrm{aq}}^{2+}$ イオンの浱度を一定にして，水素イオン濃度 を変化させた場合の水銀滴 1 滴間の電流-時間曲線から $l_{f}$ を測定 し，また水素イオン浱度を一定にして， $\mathrm{Mn}_{\mathrm{a}}^{2+}$ イオンの裖度を変 化させた場合の $l_{f}$ を測定して，図 3 および図 4 のような関係を 得た。因 3 は 反応速度定数が 水素イオン濃度に 対して一次であ り，式(8)の第 3 項を無視してもよいことを示している。また， Mn $\mathbf{n}_{\mathbf{a}}^{2+}$ イオンの濃度の逆数に対しては原点を通る直線関係が得ら れたが(図 4)，このことは，さきに $\mathrm{Cr}_{\mathrm{aq}}^{2+}$ イオンとマンガン(II)HEDTA 錯体との直接反応を無視したことが妥当であったこと を示している。

これらの切片と勾配からそれぞれの速度定数と各径路の依存性 を求めると，比較的 $p \mathrm{H}$ が低く，配位子緩衝剂としてマンガン ( I )-HEDTA および $\mathrm{Mn}_{\mathrm{aq}}^{2+}$ イオンを添加した場合の反応(1b) の主要な径路は， $j=0$ および 1 の場合でつぎのとおりである。

$$
\begin{aligned}
& {\left[\mathrm{Cr}\left(\mathrm{NH}_{3}\right)_{6}\right]^{3+}+e \longrightarrow\left[\mathrm{Cr}\left(\mathrm{NH}_{3}\right)_{6}\right]^{2+}} \\
& {\left[\mathrm{Cr}\left(\mathrm{NH}_{3}\right)_{6}\right]^{2+} \longrightarrow \mathrm{Cr}_{\mathrm{aq}}^{2+}+6 \mathrm{NH}_{3}} \\
& \mathrm{MnX}-+j \mathrm{H}^{+} \rightleftharpoons \mathrm{Mn}_{\mathrm{aq}}^{2+}+\mathrm{H}_{j} \mathrm{X}^{(3-j)-} \\
& \mathrm{Cr}_{\mathbf{a q}}^{2+}+\mathrm{H}_{j} \mathrm{X}^{(3-j)-} \underset{k_{\mathrm{H} j \mathrm{X}}^{+}}{\rightleftharpoons} \mathrm{CrX}^{-} j \mathrm{X} \\
& \quad(j=0,1) \\
& \mathrm{CrX}-j \mathrm{H}^{+} \\
& \mathrm{CrX}+e
\end{aligned}
$$

ここでは $\mathbf{C r}_{\mathbf{a q}}^{2+}$ と表わしたが，電極表面で還元された $[\mathrm{Cr}$ $\left.\left(\mathrm{NH}_{3}\right)_{6}\right]^{2+}$ イオンが完全にアンモニアを解㝑寸るかどうかにつ いては不明である。ここでは中間イオン種も含めて $\mathrm{Cr}_{\mathrm{aq}}^{2+} て ゙$ 表わ した。

正反応の速度定数 $k_{\mathrm{x}}^{+}$抢よび $k_{\mathrm{H}}^{+} \mathrm{x}$ を， $p \mathrm{H}$ の調整に用いた

酻酸緒衝塎液中の酷酸イオンによる影響を考虑して計算し，

$$
\begin{aligned}
& k_{\mathrm{X}}^{+}=5 .{ }_{7} \times 10^{10} l \cdot \mathrm{mol}^{-1} \cdot \mathrm{sec}^{-1} \\
& k_{\mathrm{HX}}^{+}=1.2 \times 10^{5} l \cdot \mathrm{mol}^{-1} \cdot \mathrm{sec}^{-1}
\end{aligned}
$$

を得た。

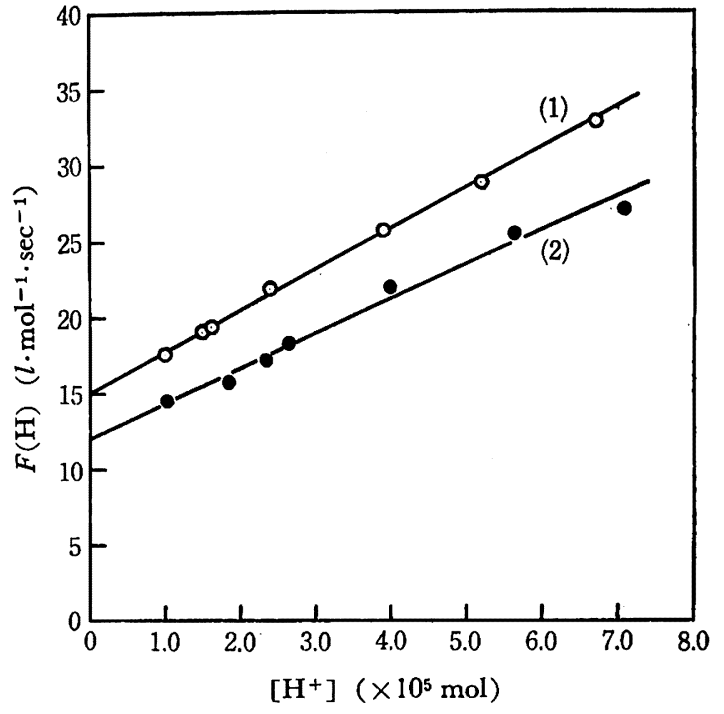

$0.500 \mathrm{mmol} / l\left[\mathrm{Cr}\left(\mathrm{NH}_{3}\right)_{6}\right] \mathrm{Cl}_{3}+0.10 \mathrm{~mol} / l$ 酶酸緩衝液 $0.006 \%$ ゼラチン+(1) $5.21_{3} \mathrm{mmol} / l$ マンガン(II)HEDTA $+0.0908 \mathrm{~mol} / l$ 塩化マンガン $(\mathbb{I}),(2)$ $7.50_{1} \mathrm{mmol} / l$ マンガン(II)-HEDTA $+0.100_{8} \mathrm{~mol} / l$ 塩化マンガン(I)

$$
\mu=1.0, \mathrm{NaCl}
$$

困 3 式 $(8)$ の $F(\mathrm{H})$ と $\left[\mathrm{H}^{+}\right]$の関係

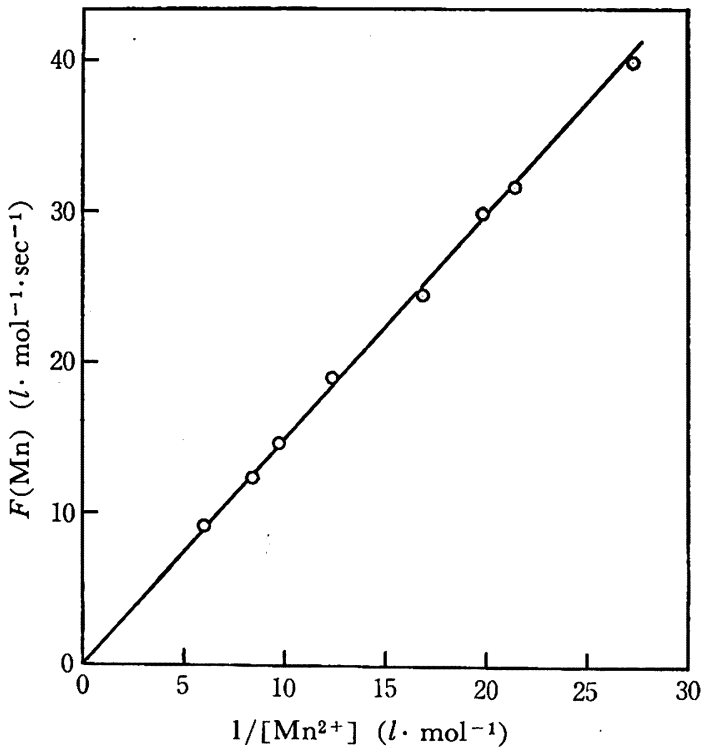

$0.500 \mathrm{mmol} / l\left[\mathrm{Cr}\left(\mathrm{NH}_{3}\right)_{6}\right] \mathrm{Cl}_{3}+0.10 \mathrm{~mol} / l$ 酶酸緩衡 液 $+5.21_{3} \mathrm{mmol} / l$ マンガン (II)-HEDTA $+0.006 \%$ ゼラチン, $\mu=1, \mathrm{NaCl}, p \mathrm{H} 4.90 \sim 4.92$

困 4 式(9)の $F(\mathrm{Mn})$ と $\left[\mathrm{Mn}^{2+}\right]$ の関係

得られた速度定数およびその比を他の文献倠 小 $^{(2)}$ と比較与る と，EDTA より NTA の值に近いが，電莎の点から判断してこ

9) N. Tanaka, K. Ebata, T. Takahari, T. Kumagai, Bull. Chem. Soc. Japan, 35, 1836(1962).

10) J. Koryta, Collection Czechoslov. Chem. Commun., 24, 3057 (1959).

11) T. J. Bydalek, M. L. Blomster, Inorg. Chem., 3, 667 (1964). 
衣 1 錯形成必応に対与る速度定数 $\left(l \cdot \mathrm{mol}^{-1} \cdot \sec ^{-1}\right)\left(25^{\circ} \mathrm{C}\right)$

\begin{tabular}{|c|c|c|c|c|c|c|}
\hline 配位子 & 金 属 & $\mu$ & $k_{\mathbf{X}}^{+}$ & $k_{\mathrm{H}}^{+} \mathrm{x}$ & $k_{\mathbf{X}}^{+} / k_{\mathbf{H}}^{+} \mathbf{x}$ & 女 献 \\
\hline HEDTA & $\mathrm{Cr}^{2+}$ & 1.0 & $5.7 \times 10^{10}$ & $1.2 \times 10^{5}$ & $4.7 \times 10^{5}$ & \\
\hline " & $\mathrm{Cd}^{2+}$ & 0.5 & - & $7.4 \times 10^{9 *}$ & - & 4) \\
\hline " & $\mathrm{Pb}^{2+}$ & 0.5 & - & $2.8 \times 10^{10 *}$ & - & 4) \\
\hline NTA & $\mathrm{Cd}^{2+}$ & 0.2 & $4.3 \times 10^{10 *}$ & $5.9 \times 10^{5 *}$ & $7.3 \times 10^{4}$ & 9) \\
\hline " & " & 0.1 & $2.0 \times 10^{10 *}$ & $7.0 \times 10^{5 *}$ & $2.9 \times 10^{4}$ & 10) \\
\hline " & $\mathrm{Ni}^{2+}$ & 1.25 & $4.8 \times 10^{5 *}$ & $7.5^{*}$ & $6.4 \times 10^{4}$ & 11) \\
\hline 配位子 & 金 属 & $\mu$ & $k_{\mathrm{H}}^{+} \mathbf{Y}$ & $k_{\mathrm{H}_{2} \mathbf{Y}}^{+}$ & $k_{\mathrm{H}}^{+}{ }_{\mathrm{Y}} / k_{\mathrm{H}_{2} \mathrm{Y}}^{+}$ & 女 献 \\
\hline EDTA & $\mathrm{Cr}^{2+}$ & 1.0 & $8 \times 10^{7}$ & - & - & 3) \\
\hline " & " & 0.5 & $2.2 \times 10^{8}$ & $2.5 \times 10^{8}$ & $8.8 \times 10$ & 12) \\
\hline " & $\mathrm{Cd}^{2+}$ & 0.1 & $8.5 \times 10^{8}$ & - & - & 13) \\
\hline " & $\mathrm{Pb}^{2+}$ & 0.2 & $3 \times 10^{9}$ & - & - & 14) \\
\hline
\end{tabular}

注 * 金属鍇体の解離反応の速度定数から算出.

のことは妥当なものと思われる。

12) N. Tanaka, A. Yamada, International Congress of Polarography, Kyoto, (1966 年 9 月) 講演; Rev. Polarog Kyoto，印刷中.

13) J. Koryta, Z. Zábransky, Collection Czechoslov. Chem. Commun., 25, 3153(1960).

14) N. Tanaka, H. Ogino, Bull. Chem. Soc. Japan, 36, 175(1963).
本研究は著者の一人(引地)が文部省内地研究員として東北大学 理学部化学科に留学中に行なったものである。この機会を与えら れた文部省ならびに終始激励して下さった福島工業高等専門学校 の江田静男教授はじめ諸先生方に厚く感謝の意を表する。

(1966 年 12 月, 東北支部常会; 1967 年 4 月, 日本化学会第 20 年会発表)

\section{微 量 硝酸イオンの分光光度定量法 一一酸性溶液で金属重鉛による還元法; Griess Romijn 試薬の応用}

（昭和 41 年 10 月 14 日受理）

小松 貞 吉・萩 野 堅*1

酸性溶液で硝酸イオンを金属亜鉛で還元し，生成された亜硝酸イオンを Griess Romijn 試薬(以下 GR 試薬と略記)で発色させ る硝酸イオンの光度定量法を検討し，ある種の塩類の共存によって亜硝酸への還元が定量的に進行することを見いだした。その结 果, 硝酸の微量が精度よく定量できた。

試料溶液 $10 \mathrm{~m} l$ を沈殿管にとり，これに $3 \mathrm{~mol} / l$ 塩化マグネシウム溶液 $2 \mathrm{ml}, 4 \mathrm{~mol} / l$ 塩化ナトリウム溶液 $1 \mathrm{ml}$ ならびに $0.1 \mathrm{~N}$ 䤏酸 $0.5 \mathrm{ml}$ を加六て酸性にする。これに粉末状金属亜鉛 400〜 $500 \mathrm{mg}$ を添加し七ンをして静かにまぜ合わせる。速心分 離後, 上澄液から $10 \mathrm{ml}$ を比色管に移し，これに GR 試薬を加えて発色させる。 $0.1 \mathrm{ppm} \mathrm{NO}_{3}-\mathrm{N}$ 以下の場合(B法)は，この 溶液の吸光度を波長 $520 \mathrm{~m} \mu$ で測定すれば濃度と吸光度は $0.005 \sim 0.07 \mathrm{ppm} \mathrm{NO}_{3}{ }^{-}-\mathrm{N}$ の範囲内で直線関保を示し，再現性よく 極微量の硝酸イオンが定量できた。また，0.1 ppm $\mathrm{NO}_{3}{ }^{-}-\mathrm{N}$ 以上の場合( $\mathrm{A}$ 法) は GR 試薬で発色させたのち，これに $\mathbf{3}$ 造化 フンモニウム溶液 $2 \mathrm{ml}, 10 \%$ EDTA.2 Na 溶液 $7 \mathrm{ml}$ ならびに $9 \mathrm{~N}$ フンモニア水 $1 \mathrm{ml}$ を添加してフルカリ性にし, その吸光度 を波長 $480 \mathrm{~m} \mu$ で測定すれば， $0.05 〜 2.5 \mathrm{ppm} \mathrm{NO}_{3}^{-}-\mathrm{N}$ の範囲内で直線関係が得られ，定量範囲が拡大された。

亜硝酸イオン共存の場合の硝酸イオンの定量法についても実験し，好結果をおさめた。

\section{1 緒宣}

著者はさきに微量の硝酸イオンの定量法として，金属亜鉛によ る還元法をアンモニア性溶液において行ない，満足できる結果1 を得た。アルカリ性溶液の反応は一般に妨害イオンが多く，こと に重金属イオンは沈股を生じやすく，そのため定量操作も複雑に なるきらいがある。それゆえ今回は酢酸酸性溶腋でこの還元法を 検討してみた。酸性溶液におけるこの還元法に関しては従来もし

\footnotetext{
*1 Sadakichi Komatsu, Ken Hagino 秋田大学教育学部 化学科, 秋田市手形学園町

1) 萩野 堅, 日化, 82,841(1961).
}

ばしば報告がある。しかし従来の報告によれば，硝酸の邆元生成 物としては，覀硝酸のほかにさらに低級の酸化状態の化合物が生 じ，その結果，悪硝酸の生成率は 40～85\%23程度になるといわれ ている。このように亜硝酸の生成本が比效的低く，またその生成 量も一定になり難く，したがって再現性に乏しくなるなどの点か ら，酸性溶液における硝酸の要鉛による㣎元法には，なお検尌を 要する問題が種々含まれているように考えられる。しかし一方,

2) 加藤多喜雄, 冲中 裕, 堺敬一, 分析化学, 3,235 (1954); J. B. Mullin, J. P. Riley, Anal. Chim. Acta, 12, 464(1955); A. Henriksen, Analyst, 90, 83(1965).

3) 萩野 堅, 日化, 82,838(1961). 